Article

\title{
Treatment of Head Louse Infestation with a Novel Mixture Made of Semi-Crystalline Polymers and Plant Extracts: Blind, Randomized, Controlled, Superiority Trial
}

\author{
José Henrique Leal Cardoso ${ }^{1}$, Andrelina Noronha Coelho de Souza ${ }^{2}$, \\ Francisco Militão de Souza ${ }^{3}$, Samia Sa Preire ${ }^{4}$ and Claire Pinçon ${ }^{5, *}$ \\ 1 Department of Physiology and Pharmacology, State University of Ceará, Avenue Paranjana 1700, \\ Fortaleza 60740-000, Brazil; jh.lealcardoso@gmail.com \\ 2 Laboratory of Electrophysiology, Superior Institute of Biomedical Sciences, State University of Ceará, \\ Avenue Paranjana, 1700 Campus of Itaperi, Fortaleza 60740-903, Brazil; andrelinanoronha@gmail.com \\ 3 Veterinary Faculty, State University of Ceará, Avenue Paranjana 1700, Fortaleza 60740-000, Brazil; \\ fmilitao@secrel.com.br \\ 4 Faculty of Medicine of the State University of Ceará, Avenue Paranjana 1700, Fortaleza 60740-000, Brazil; \\ ssf.militao@gmail.com \\ 5 Univ. Lille, CHU Lille, ULR2694 (METRICS: évaluation des technologies de santé et des pratiques \\ médicales), F-59000 Lille, France \\ * Correspondence: claire.pincon@univ-lille.fr; Tel.: +55-16-3315-9120
}

Received: 6 March 2020; Accepted: 3 April 2020; Published: 10 April 2020

\begin{abstract}
The rate of head louse infestations is increasing. Most of the neurotoxic treatments are not reliably ovicidal and are faced with genetic resistance. The treatments based on a mechanical mode of action show no sufficient efficacy, transferring the chances of a cure on a tedious combing or leaving the hair fatty. This double-blinded, randomized, controlled, superiority trial evaluates the efficacy and safety of a novel mixture made of semi-crystalline polymers and plant extracts. Forty-five participants received a single application of either $1 \%$ Permethrin lotion or the novel lotion, applied for 15 minutes. Untreated and treated nits were collected and placed in an incubator during 10 days. The worst case intent-to-treat analysis found the novel lotion significantly more effective than $1 \%$ Permethrin, with 21/22 (95.5\%) participants cured and 9/23 (39.1\%), respectively $(p<0.0001)$. Rate of viable nymphs was 0.5 (2.1) for the new lotion and 40.8 (20.4) for the $1 \%$ Permethrin. The new lotion cures head louse infestations, offering an effective alternative treatment, with a high efficacy for inhibiting the hatching of eggs. Its physical actions on lice and their eggs should not be affected by resistance to neurotoxic insecticides.
\end{abstract}

Keywords: head lice; treatment; shampoo; Pediculus humanus capitis; clinical trial; clinical study; randomized; blinded; controlled

\section{Introduction}

Head louse infestations are frequent among children 3-11 years of age and may induce skin irritation, superinfection from scratching, social stigmatization, and psychological distress [1]. Moreover, head louse infestations cause high levels of anxiety among the parents of school-aged children [2]. An increased rate of head louse infestations in recent years has been reported from North and South America, Australia, and in some countries in Europe and Asia [3]. For remedies, various pediculicidal treatments in external use exist across the world. 
The first generation of anti-lice treatments, developed from the forties, has a neurotoxic action. Those treatments are essentially composed by organophosphate insecticides (malathion) and by pyrethroids (e.g., pyrethrins, phenothrin, and permethrin). Permethrin $1 \%$ lotion is still the first-line pharmacologic treatment of pediculosis. Those treatments, registered as drugs, are still preponderant in the United States and South America markets but not commonly used in Europe.

Regarded as an alternative to conventional treatments, the second generation of anti-lice treatments is based on a mechanical mode of action, claiming suffocation [4,5] and/or dehydration [6] of parasites. The main components of those treatments are derived from mineral oils-more particularly, from silicon (e.g., dimethicone or cyclopentasiloxane)—or from vegetable oil (coconut oil, neem oil, etc.) with, sometimes, essential oils (lavender, tea tree, anise, geranium, etc.). Those products, registered as medical devices, are widely used in Europe and in other countries of the continent.

Most of the treatments based on a neurotoxic mode of action are not reliably ovicidal, because nits have no nervous system at their first stage of development and, consequently, require two or more treatment cycles to eradicate lice infestation [7]. Furthermore, some neurotoxic insecticides face with genetic resistance developed by the parasites $[3,8,9]$. The efficacy of treatments based on a mechanical mode of action is not enough, demonstrated especially for vegetable oil-based therapeutics. Clinical trials conducted on this kind of treatment shows contradictory results [10-12] or a great variability in the cure rate $[6,9,13-15]$.

Moreover, anti-lice treatments present various specific cons for users: the several applications required, long exposure time, chances of successful treatment transferred on a rigorous and long combing, essential oils may cause severe irritations or allergies, and, finally, products which are made up of mineral oils are difficult to remove from the hair, leaving them fatty. For these reasons, there is a strong wish, among the parents of children likely to be affected by head lice, for a reliable and non-greasy product which can eradicate both lice and eggs in a single application, with no tedious combing-furthermore impractical in some cases regarding the hair type.

As a potential alternative, we chose to study a novel anti-lice lotion made up with a Brazilian plant, Protium heptaphyllum (Aubl.) Marchand. It belongs to the Burseraceae family, which has 18 genera and around 700 species, distributed throughout three different tribes: Canarieae, Protieae, and Bursereae. This species is located at places with low altitude and without intense cold, including tropical, drought forests, and deserts [16].

Protium heptaphyllum is a tree present all over Brazil, especially in damp or dry, sandy soil areas. It is evergreen or semideciduous and aromatic, with a height of $10 \mathrm{~m}$ to $20 \mathrm{~m}$ and stem of $40 \mathrm{~cm}$ to $60 \mathrm{~cm}$ in diameter. It is found mainly in the Amazon region and in some northeastern states, such as Bahia, Ceara, and Piauí, and other countries of South America (Colombia, Paraguay, Suriname, and Venezuela) [17].

It is popularly known as almecegueira, breu-branco verdadeiro, almecegueira-cheirosa, almecegueira-de-cheiro, and almecegueiro-bravo [18].

An oily resin is produced when the trunk of Protium heptaphyllum is injured or naturally exuded. This resin hardens in contact with air humidity. This exudate has a greenish-white coloration $[19,20]$.

Within the plant, the resin plays many roles and, in particular, as a cicatrizing agent [21]. In its natural state, the essential oil contained in the resin allows the plant to defend itself against the colonization of external pathogens. The resin protects the plant from insect bites, desiccation, UV radiation, and high temperatures, especially in young leaves and stems [22]. It is through a process of coating that tree trunks heal their abrasions in the Amazon. It is also in the adaptive strategy of certain plants in tropical environments, to avoid evapotranspiration.

It is generally used in popular medicine for its anti-inflammatory activity [23], analgesic [24], expectorant, and wound-healing properties [25]. Protium heptaphyllum is also known for antimicrobial [26], hepatoprotective, antinociceptive, and gastroprotective properties [27].

The properties of the Protium heptaphyllum resin are similar to the resins produced by species of Boswellia found in India and Africa. At the natural state, the resin consists of a large number of 
monoterpenes, such as limonene (16.9\%), $\alpha$-phellandrene $(16.7 \%)$, terpinolene $(28.5 \%)$, and by $\alpha$-pyrene $(10.5 \%)$. More specifically, the resin is composed of a mixture of triterpenes from the $\alpha$-amyrin (ursane) and $\beta$-amyrin (oleane) series and an essential oil, rich in monoterpenes and sesquiterpenes $[25,28,29]$ (see Figure 1).

Protium heptaphyllum is classified as: Binding, Masking - CAS Number: 92704-59-1 EINECS/ELINCS No: 296-493-7 COSING REF No: 83225

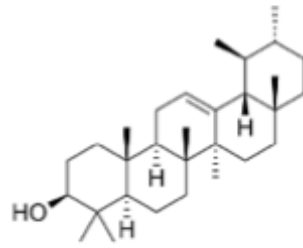

$\alpha$-amyrine

No CAS: 638-95-9

$\mathrm{N}^{\circ} \mathrm{CE}: 211-352-1$

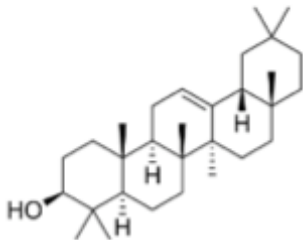

$\beta$-amyrine

No CAS: 559-70-6

$\mathrm{N}^{\circ} \mathrm{CE}:$ 209-204-6

Resin (essential oil): $\alpha$-pinene, 1,3-pentadiene, myrcene, $\alpha$-phellandrene, $O$-methylanisol, $\alpha$-terpinene, $p$-cymene, limonene, 1,8-cineole, $\gamma$-terpinene, $\alpha$-terpinolene, linalool, $p$-menth-1,5,8-triene, camphor, carvacrol, terpinen-4-ol, $p$-cymen-8-ol, $\alpha$-terpineol, 2,5-dimethoxy-benzene, 3,5-dimethoxybenzene, $\delta$-elemene, $\alpha$-ylangene, $\alpha$-cubebene, $\alpha$-copaene, $\beta$-bourbunene, $\beta$-elemene, methyl eugenol, $\alpha$-gurjunene, 2,3,5-trimethoxytoluene, $\beta$-caryophyllene, $\gamma$-elemene, $\alpha$-humulene, alloromadendrene, germacrene D, $\beta$-selinene, $\alpha$-selinene, viridiflorene, $\alpha$-muurolene, $\beta$-bisabolene, $\delta$-cadinene, $\gamma$-cadinene, myristicin, $\alpha$-calacorene, elemicin, caryophyllene oxide, $1,2,3,4$ tetramethoxy-5(2)-propenylbenzene, humulene epoxide, tetradecanal, dilapiol, $\delta$-cadinol, selin-11-en-4 $\alpha$-ol, apiol, p-menth-3-en-1,2,8-triol.

Resin (fixed oil): $\alpha$-amyrin, $\beta$-amyrin, brein, maniladiol, $\alpha$-amyrone, $\beta$-amyrone, lupenone, $3 \beta, 24$-dihydroxy-

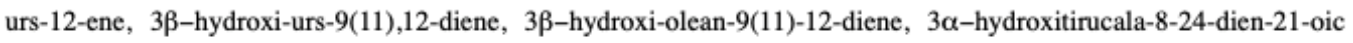

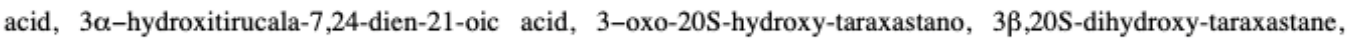
friedelin, epi- $\Psi$-taraxastanonol, epi- $\Psi$-taraxastanodiol, $3 \beta$-dihydroxy-urs-12-ene.

Figure 1. Chemical information about Protium heptaphyllum.

The resin is often used in cosmetics as a perfume or as a make-up product, forming a kind of lacquer obtained by kneading the resin with a dye and a dissolving grease. The resin, transferred in a lipophilic support, is also suitable for skin care, hair care, and nail care applications. It is a film-forming agent and a tensor.

\section{Materials and Methods}

Participants were recruited from a resource-poor community in Fortaleza (capital of Ceará State, Northeast Brazil). Population-based studies in European countries show diverging prevalence, ranging from $1 \%$ to $20 \%$ [30]. Studies conducted in Northeastern Brazil report a high prevalence of pediculosis capitis among the general population, over $40 \%$ [31]. These data represented a strong argument in favor of conducting robust clinical trials to test the effectiveness of a pediculicidal treatment. Participants were recruited via school visits and an oral presentation of the study during a week one month before the start of the clinical trial.

\subsection{Treatments Used in This Study}

In this study, the efficacy and the safety profile of a new anti-lice lotion were compared to a neurotoxic standard treatment in Brazil.

This standard treatment is composed by Permetrin $1 \%(10 \mathrm{mg})$ and excipients: carbomer, isopropyl alcohol, methylparaben, propylparaben, cocoamidopropyl betaine, simethicone, sodium hydroxide, sodium lauryl sulfate, propylene glycol, and purified water (manufacturer: CIMED INDÚSTRIA 
DE MEDICAMENTOS LTDA, Av. Cel. Armando Rubens Storino, 2750 - CEP 37550-000 - Pouso Alegre - MG).

The new product is an oily single-phase lotion composed by deterpenated Protium heptaphyllum resin (active ingredient 1,5\%), extracted by a solvent, and concentrated in a lipophilic support, grape seed oil, 55\% (emollient). The other ingredients are latent surfactants, Laureth-4 and Comamide MIPA (Eur-Amid N2®, 40\%), and Citrus aurantium dulcis peel wax 3,5\%, a natural antioxidant and antimicrobial agent [32], which acts in the formula as preservative and mixture stabilizer (manufacturer: LABORATOIRES MARIE-LOUISE / DUHOT sprl., Passage des Travailleurs du Livre 2/22, 7500 Tournai - BE).

In the new lotion, the resin is treated. Once the resin is harvested, the essential oil, rich in volatile terpene compounds, is separated by hydrodistillation. So, the resin is deterpenated for a first time, which makes it possible to evaporate the essential oil. Then, the undistilled paste is recovered. The extracted resin presents a crude mixture of pentacyclic triterpenes, represented mostly by amyrine in the $\alpha$ and $\beta$ form. This mixture is solubilized in alcohol (ethanol) at $96^{\circ}$ with stirring at $40{ }^{\circ} \mathrm{C}$ in the ratio 1:3. This process allows a very fine filtering of the dissolved resin. The ethanolic extract is filtered again and concentrated by evaporation of the ethanol under vacuum in order to obtain an extract containing $62.3 \%$ of the resin. Finally, the resin is transferred to vegetable oil (mixture of resin and oil), stirred, and decanted for $2 \mathrm{~h}$, which allows the obtention of an optimal transfer rate of $80 \%$. The resin in oil is passed through molecular distillation in order to remove the last volatile compounds. So, it is deterpenated again. The objective of this step is to remove all of the monoterpenes, because the latter have a plasticizing effect, which counteracts the stiffening of the resin. Consequently, there is no more residual monoterpenes (e.g. limonene or linalool) in the mixture, which has no skin-sensitizing, no allergens.

\subsection{Ethics}

A participant information booklet (PIB) was submitted to responding families. Those who wished to enroll came to the school for a detailed oral presentation on pediculosis and the study steps $48 \mathrm{~h}$ before the recruitment day (Day 0). The day of recruitment, verbal consent has been asked to check for the presence of live head lice. Each eligible participant had signed consent and assent procedure was followed. A free and enlightened consent form was provided to parents or guardians of children younger than 16 years, and oral assent was asked of children too. A special form has been provided to explain the objective and the course of the study, with a vocabulary adapted to the age of the participants. All participants stated that they understood the purpose and requirements of the investigation before giving written consent. For any child identified as infested by lice, but who was unable to participate in the study for any reason, a standard treatment was offered. All adverse events were monitored during the study, and all changes in concomitant illness and medication were recorded. A completion/withdrawal form was completed at the end of the study period. At the end of the clinical trial, patients not $100 \%$ cured were properly treated by a rigorous combing and were provided with a standard treatment. No payment was offered for participation.

The study was conducted under local institutional review and in accordance with the Declaration of Helsinki, the European standard DIN EN ISO 14155:2012-01 (clinical investigation of medical devices for human subjects-good clinical practice), the GCP Regulation, the National Commission for Research Ethics (C.O.N.E.P.), the CNS Resolution number 466 of 2012 and the CNS Operational Norm number 001 of 2013. This is a study of CE-marked medical devices, which were not modified and not used outside of their CE-marked intended purposes and do, therefore, not require ethic approval, which is also applicable for studies in Brazil.

\subsection{Design}

This clinical trial was designed to evaluate the efficacy and confirm the safety of an anti-lice lotion in a single application with a new mechanical mode of action. The product was tested in comparison 
with a WHO standard treatment acting by neurotoxic mode (Permethrin 1\%) in order to discriminate if one treatment was superior to another (superiority test). Our study was double-blinded, and the products looked sufficiently similar to allow double-blinding.

The first objective was to evaluate the efficacy on lice immediately after treatment removal (Day 1), the day after (Day 2), and one week later (Day 8). In vivo data were compared with data from an in vitro study, designed to examine the specific efficacy of the two lotions on eggs hatching, in comparison with a control group consisting of untreated nits. The second objective was to confirm the safety profile of the new product with a dermatologist examination of every participant scalp at each stage of the study.

All enrolled participants (Figure 2) provided baseline data on age, gender, hair characteristics, siblings, and previous pediculicide use. Three years old was the lower age limit. There was no upper limit.

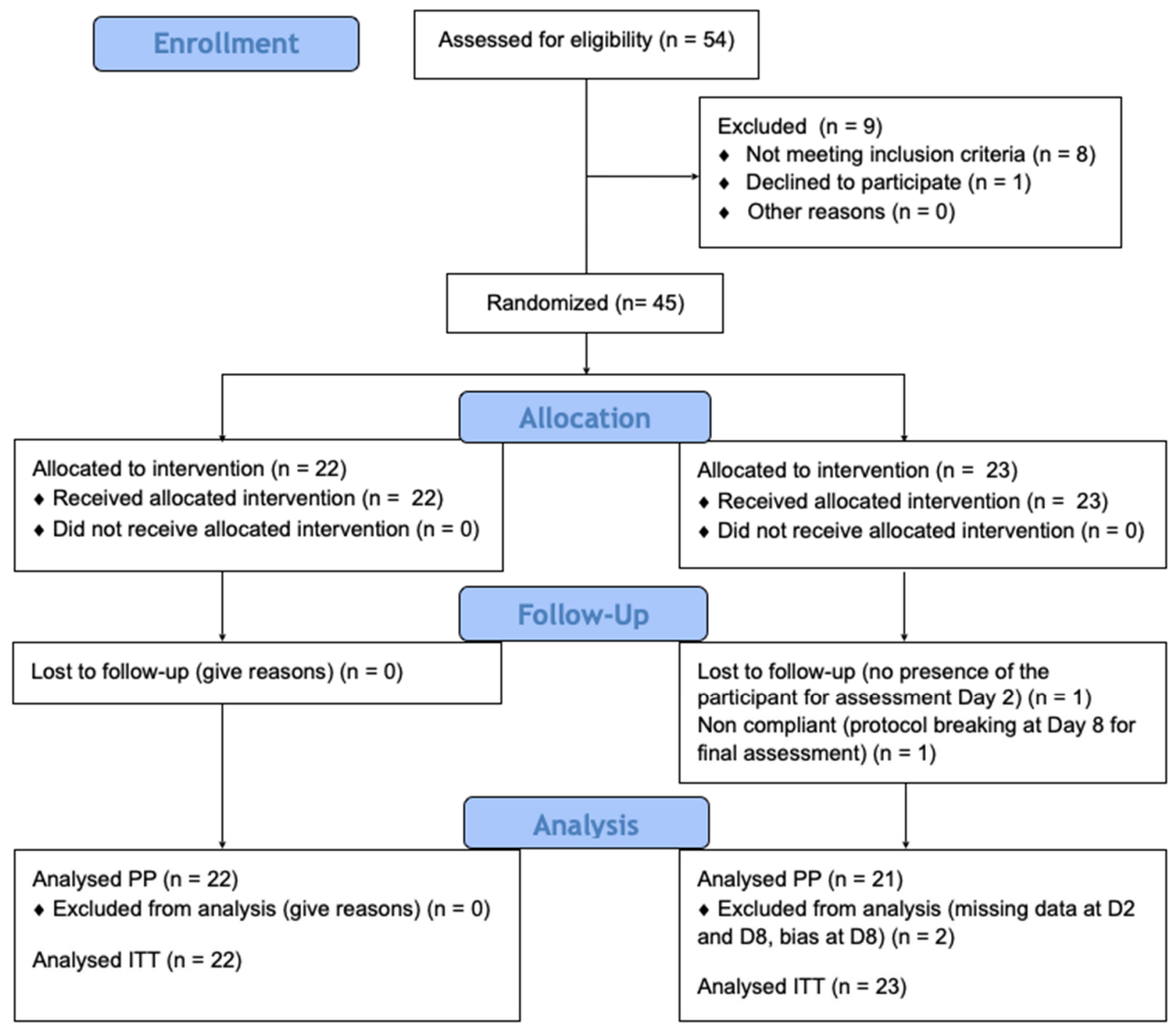

Figure 2. Enrollment process.

Trained investigators used a visual and manual protocol to examine participants for head lice presence. Infestation degree was determined by the number of alive lice found on each participant after standardized combs strokes, using a fine-toothed plastic detection comb as recommended by Balcioglu et al. [31]. Light infestation was defined as 1 louse to 3 lice found after 3 comb strokes, moderate infestation as 4 to 6 lice found after 3 comb strokes, and heavy infestation as more than 7 lice found after 3 comb strokes.

Participants who, after examination, were confirmed to be infested by lice and who had at least 5 visible nits found in the part of the hair closer than $1.0 \mathrm{~cm}$ from the skull were eligible. Participants were also required to confirm their availability for the duration of the study ( 8 days following the 
treatment) in order to be included in the study. Exclusion criteria were known to be sensitivity to any of the ingredients; secondary bacterial infestation of the scalp (e.g., impetigo) or presence of any disease of the scalp (e.g., psoriasis or eczema); pregnant or breast-feeding; participation in another clinical trial within 1 month before entry to this study; use of hair bleach, color, or permanent wave products within the previous four weeks; use of any type of pediculicide during the 15 days before the initiation of the treatment, and treatment by antibiotics.

All procedures, including preliminary tests, were conducted at school. Experimental and positive products were supplied in $120 \mathrm{~mL}$ bottles. The day of the intervention (Day 1), a standard allergy test was performed on the right and left arms on each participant. Experimental and positive products were left in contact to the skin of the elbow during 20 minutes. Then, the participants were randomly allocated into group "treatment A" (new product) or into group "treatment B" (Permethrin 1\% lotion). Assignment was consigned on a specific form by an independent observer, in case of adverse event. Patients, practitioners, and assessors were blind to the treatment group.

Each treatment was applied at the same time in two separate rooms. Members of the school staff applied the treatments under supervision of members of the study team, after a good understanding of each practitioner was checked. Each product was applied on dry hair, using enough to thoroughly moisten the hair and scalp. Treatments were applied to the full hair length and left for 15 minutes. After the application time, the hair of participants was wetted (water spray) during one minute. Finally, each treatment was removed using a normal shampoo, and only 15-20 comb strokes were given on half the head of each participant, in order to examine lice conditions.

To provide diagnostic snapshot data of the status of infestation, lice found were removed and fixed to the case record (participant's Case Report Form - CRF) using clear tape. Each louse was taped, mentioning the development stage (immature or adult) and state (live or dead). Death was appreciated using the observation grid established by the Department of Parasitology of the University of Tours (France). Only K-D3+ (no visible movement, except some sporadic intestinal movements) and $\mathrm{K}-\mathrm{D} 4+$ (no visible movement, so external as internal, except a tiny contraction of the digestive tract after stimulation by a clamp) were registered as dead, whereas lice presenting strong anomalies of movements compared as still capable of turning around when on their backs were considered as alive. Lice still capable of some movements internal or external and turning around with difficulty when on their backs were also considered as alive.

In order to determine the cure rate, a meticulous combing was performed on Day 2 (one day after treatment). Examinations were made using the comb across the whole scalp. At Day 8 (final assessment), a more extensive examination was made to try to ensure no lice were present. At each assessment, the participant's hair and scalp were visually examined and combed with a head louse comb (plastic teeth), and, as at Day 1, any louse found were taped (with clear tape) into the participant's CRF. All participants were examined at days 1,2, and 8, unless they were lost to follow up.

Criterion specified for a cure was "no living lice at D1 and D2 and no living immature at D8". We also performed analyses on the following separate criteria: "absence of alive lice on D8", "absence of living immature on D8", "absence of alive lice and alive immature on day 2", and "absence of alive lice and immature lice on D1". Criterion for exogenous reinfestation was "no alive lice found after the treatments at day 1 and day 2; and, on day 8, no more than four adult lice and no nymph found during combing".

Considering that ovicidal efficacy outcomes of pediculicides are often not reliable because they are only assessed indirectly (e.g., observing the number of lice at premature stages found on a head several day after treatment, indicating inefficacy on nits), we designed an in vitro study in order to alleviate this difficulty. To examine the specific efficacy of the two lotions on the eggs, several nits (depending on the infestation degree) were collected on each participant before treatment (during the diagnosis) and then put in an incubator at $32 \pm 1{ }^{\circ} \mathrm{C}$ and $54 \%$ relative humidity, in order to be the control group. Several nits (depending on the infestation degree) were collected on each participant after treatment removal at day 1 . To respect the parsimony principle, only visible full nits were taken by cutting a 
hair lock. Each day, during ten days, the hatching rate was examined (counting hatched eggs and determining the viability of nymphs by their survival $3 \mathrm{~h}$ after hatching) in the two treatment groups and compared with the control group. The number of hatches was clearly taped in a specific file.

\subsection{Statistical Analysis}

For sample size determination, we anticipated that there was likely to be a disparity in efficacy between the new semi-crystalline lotion and Permethrin 1\% lotion, based on previous data (in vitro studies for the experimental product and data available in the literature for permethrin). For a randomize-by-individual approach, a sample size of 17 per group was estimated to have at least $80 \%$ power with a type I error rate (one-sided) of $2.5 \%$ to detect a difference of $38 \%$ between the success rates for the experimental lotion and $1 \%$ Permethrin, based on a $98 \%$ success rate for the experimental lotion (in vitro test) and evidence suggesting lower success rates with $1 \%$ Permethrin (mean of $62.5 \%$ according to available data) [33-43].

Recoding of inclusion criteria was:

- Processing: A: 0, B: 1

- Gender: F: 0, M: 1

- Hair length: short: 0, shoulders: 1, below shoulders: 2

- Hair type: frizzy: 0, curly: 1, straight: 2, flexible: 3

- Scalp at inclusion: normal: 1

- Antibiotic treatment before: no: 0

- Infestation: low: 1 , moderate: 2 , high: 3

Comparisons of the two populations were performed by a Student's $t$-test or Mann-Whitney test for continuous variables (the normality of the variables was tested by a Shapiro-Wilk test) and by chi-square tests or Fisher for categorical variables.

For in vivo outcomes, the endpoints are presented as numbers (proportions) and the difference in rates (A Treatment-B Treatment) was estimated by a 95\% bilateral confidence interval. It was possible to conclude that the superiority of treatment A vs. treatment B if the lower limit of the confidence interval was strictly positive.

For in vitro outcomes, the evolution over time of the cumulative hatching rate and the cumulative rate of viable nymphs were investigated by a generalized linear model with repeated measures (PROC GLIMMIX), including the time from the collection, and with an autoregression(1) covariance matrix structure for repeated measurement. The odds-ratio of treatment A vs. treatment B for hatching and viable nymphs was estimated by a bilateral confidence interval of $95 \%$, and we could conclude to the superiority of treatment A vs. treatment B if the upper bound of the confidence interval was strictly less than 1 . The type I error rate was set at $2.5 \%$ (one-sided) for the superiority analysis and $5 \%$ (two-sided) for other analyses. The analyses were performed by intent-to-treat; per protocol analysis was also conducted to supplement the results. All analyses were performed with SAS software (SAS v9.4 SAS Institute).

\section{Results}

Our study was carried out in August 2016. Forty-five young people aged 6 to 10 years agreed to take part and met the eligibility criteria. The two groups were similar in age, sex, intensity of infestation, and hair length and degree of curl. No adverse events occurred. Before treatment, 13 (29\%) participants had heavy louse infestations, 12 (27\%) medium infestations, and $20(44 \%)$ light infestations (Table 1). According to the weighing of the bottles after application, $67 \mathrm{~mL}$ of product were used on average, with a maximum of $92 \mathrm{~mL}$ for the experimental product and $90 \mathrm{~mL}$ for the treatment with Permethrin $1 \%$. 
Table 1. Baselines. Number (proportion) or median (interquartile range). No significant difference between the two populations.

\begin{tabular}{|c|c|c|c|c|}
\hline & & $\begin{array}{l}\text { Total Sample } \\
\quad(n=45)\end{array}$ & $\begin{array}{l}\text { Treatment A } \\
\quad(n=22)\end{array}$ & $\begin{array}{c}\text { Treatment B } \\
\quad(n=23)\end{array}$ \\
\hline \multicolumn{2}{|l|}{ Gender F } & $38(84 \%)$ & $18(82 \%)$ & $20(87 \%)$ \\
\hline \multicolumn{2}{|l|}{ Age (years) } & $8(7-9)$ & $8(6-9)$ & $8(7-10)$ \\
\hline \multicolumn{2}{|l|}{ Sibling } & $1(1-2)$ & $2(1-2)$ & $2(1-3)$ \\
\hline \multicolumn{5}{|l|}{ Hair length } \\
\hline \multirow{7}{*}{ Hair type } & Short & $8(18 \%)$ & $4(18 \%)$ & $4(17 \%)$ \\
\hline & On the shoulders & $3(7 \%)$ & $1(5 \%)$ & $2(9 \%)$ \\
\hline & Under the shoulders & $34(76 \%)$ & $17(77 \%)$ & $17(74 \%)$ \\
\hline & Crinkly & $22(49 \%)$ & $10(45 \%)$ & $12(52 \%)$ \\
\hline & Curly & $8(18 \%)$ & $6(27 \%)$ & $2(9 \%)$ \\
\hline & Straight & $14(31 \%)$ & $6(27 \%)$ & $8(35 \%)$ \\
\hline & Flexible & $1(2 \%)$ & $0(0 \%)$ & $1(4 \%)$ \\
\hline \multicolumn{2}{|l|}{ Normal scalp } & $45(100 \%)$ & $22(100 \%)$ & $23(100 \%)$ \\
\hline \multicolumn{2}{|c|}{ Antibiotic treatment before inclusion } & $0(0 \%)$ & $0(0 \%)$ & $0(0 \%)$ \\
\hline \multirow{3}{*}{ Lice infection degree } & Low & $20(44 \%)$ & $8(36 \%)$ & $12(52 \%)$ \\
\hline & Moderate & $12(27 \%)$ & $6(27 \%)$ & $6(26 \%)$ \\
\hline & Strong & $13(29 \%)$ & $8(36 \%)$ & $5(22 \%)$ \\
\hline
\end{tabular}

\subsection{Cure rate of the Two Treatments for the In Vivo Part of the Study}

The primary analysis was an intent-to-treat and involved all patients who were randomly assigned (45 participants). The secondary analysis was per-protocol. One participant in the treatment B group was lost to follow-up at Day 2 and at Day 8. One patient was considered a protocol violator in the treatment $B$ group; consequently, forty-three patients remained for the per protocol analyses.

We performed analyses on each different healing criterion: absence of live lice on D8, absence of living immature on D8, absence of live lice and live immature on D2, absence of live lice and live immature on D1 and, then, absence of live lice on D1 and on D2 and absence of live immature on D8. We also performed specific analyses on the hatching rate of nits and the rate of viable immatures.

\subsubsection{Results for the Criterion "Absence of Live Lice on D8"}

Four children with exogenous re-infestations according to the protocol definition were identified \#19, \#22, \#27 (treatment A), and \#52 (treatment B). They were considered either as successes (intent-to-treat (ITT) with re-infestations) or as failures for a sensitivity analysis (ITT, without re-infestations).

In ITT, regarding the "worst case" and under the efficacy criterion "no living lice at D8", data show a $95.5 \%$ success for the new pediculicide against $52 \%$ for the standard treatment (Permethrin $1 \%$ ). The difference (IC95\%) between the two treatments is $43.3(16.0 ; 67.3)$, with $p$-value A vs. B of 0.0005 . For per protocol (PP), results are the same for the new treatment and $47.6 \%$ for the Permethrin $1 \%$ lotion (Table 2).

The multivariate binary logistic regressions show an adjusted treatment effect whatever the set of analyses (Table 3): treatment A multiplies the chances of recovery by 11, 42, or 53 depending on the samples considered, regardless of the degree of hair infestation. Results also highlight an effect of the degree of infestation: a heavy infestation divides the risk of healing by $1 / 0.077=13,1 / 0.062=16$, or $1 / 0.059=17$, depending on the samples considered, regardless of the treatment. No interaction between the treatment and the degree of infestation has been demonstrated, which means that it has not been possible to show that the effectiveness of a treatment varies with the degree of infestation. 
Table 2. Comparison of success rates on D8. ITT: intent-to-treat and PP: per protocol.

\begin{tabular}{cccccc}
\hline & Treatment A & Treatment B & Difference (IC95\%) & $p$ Sup A vs. B & $p$ Sup B vs. A \\
\hline \multicolumn{5}{c}{ Without considering exogenous re-infestations, which are then considered as failures } \\
ITT, worst-case for A & $18 / 22(81.8 \%)$ & $11 / 23(47.8 \%)$ & $34.0(5.8 ; 60.0)$ & 0.009 & 0.991 \\
ITT, worst-case for B & $18 / 22(81.8 \%)$ & $9 / 23(39.1 \%)$ & $42.7(14.2 ; 67.2)$ & 0.002 & 0.998 \\
PP & $18 / 22(81.8 \%)$ & $9 / 21(42.9 \%)$ & $39.0(7.8 ; 63.8)$ & 0.004 & 0.996 \\
EP & Excluding children with exogenous re-infestations \\
ITT, worst-case for A & $18 / 19(94.7 \%)$ & $11 / 22(50.0 \%)$ & $44.7(14.1 ; 68.6)$ & 0.001 & 0.999 \\
ITT, worst-case for B & $18 / 19(94.7 \%)$ & $9 / 22(40.9 \%)$ & $53.8(24.2 ; 75.8)$ & 0.0002 & 0.9998 \\
PP & $18 / 19(94.7 \%)$ & $9 / 20(45.0 \%)$ & $49.7(21.2 ; 74.0)$ & 0.0004 & 0.9996 \\
By including children with exogenous re-infestations and considering them as successful & 0.9995 \\
ITT, worst-case for A & $21 / 22(95.5 \%)$ & $12 / 23(52.2 \%)$ & $43.3(16.0 ; 67.3)$ & 0.0005 & 0.9999 \\
ITT, worst-case for B & $21 / 22(95.5 \%)$ & $10 / 23(43.5 \%)$ & $52.0(25.7 ; 74.3)$ & 0.0001 & 0.9997 \\
PP & $21 / 22(95.5 \%)$ & $10 / 21(47.6 \%)$ & $47.8(17.6 ; 70.4)$ & 0.0003 & \\
\hline
\end{tabular}

Table 3. Binary logistic regressions. The odds ratios for the absence of live lice are given on D8 from the multivariate analyses. A factor is beneficial if OR $>1$.

\begin{tabular}{|c|c|c|c|}
\hline & OR & IC95\% & $p$ \\
\hline \multicolumn{4}{|c|}{ Without considering exogenous re-infestations, which are then considered as failures } \\
\hline \multicolumn{4}{|c|}{ Worst-case analysis for A } \\
\hline $\begin{array}{c}\text { Treatment } \\
\text { treatment } B \\
\text { treatment } A\end{array}$ & $\begin{array}{l}\text { Reference } \\
11.039\end{array}$ & $(1.887 ; 64.577)$ & 0.008 \\
\hline Infestation & Reference & & \\
\hline Low & 0.214 & $(0.034 ; 1.350)$ & 0.10 \\
\hline $\begin{array}{c}\text { Moderate } \\
\text { High }\end{array}$ & $\begin{array}{l}0.214 \\
0.077\end{array}$ & $(0.010 ; 0.598)$ & 0.01 \\
\hline \multicolumn{4}{|c|}{ Excluding children with exogenous re-infestations } \\
\hline \multicolumn{4}{|c|}{ Worst-case analysis for A } \\
\hline $\begin{array}{c}\text { Treatment } \\
\text { treatment } B \\
\text { treatment } A\end{array}$ & $\begin{array}{l}\text { Reference } \\
41.857\end{array}$ & $(2.985 ; 587.019)$ & 0.006 \\
\hline Infestation & Reference & & \\
\hline Low & 0.210 & $(0.027 ; 1.636)$ & 0.14 \\
\hline $\begin{array}{c}\text { Moderate } \\
\text { High }\end{array}$ & 0.062 & $(0.005 ; 0.774)$ & 0.03 \\
\hline \multirow{2}{*}{\multicolumn{4}{|c|}{$\begin{array}{l}\text { By including children with exogenous re-infestations and considering them as successful } \\
\text { Worst-case analysis for A }\end{array}$}} \\
\hline & & & \\
\hline $\begin{array}{l}\text { Treatment } \\
\text { treatment } B \\
\text { treatment } A\end{array}$ & $\begin{array}{l}\text { Reference } \\
53.044\end{array}$ & $(3.714 ; 757.547)$ & 0.003 \\
\hline Infestation & Reference & & \\
\hline Low & 0.188 & $(0.024 ; 1.453)$ & 0.11 \\
\hline $\begin{array}{c}\text { Moderate } \\
\text { High }\end{array}$ & 0.059 & $(0.005 ; 0.720)$ & 0.03 \\
\hline
\end{tabular}

\subsubsection{Results for the Criterion "Absence of Living Immature on D8"}

The results show that treatment A cured $100 \%$ of the children. It was not possible to build logistic regression models with this treatment, since all the children treated with A were successful. In ITT regarding the "worst case" and under the efficacy criterion "no living immature lice at D8", data showed $100 \%$ efficacy for the new treatment and $39.1 \%$ for the standard treatment, with difference between the two products of $60.9(35.8 ; 80.9)$, p sup A vs. B $<0.0001$ (Table 4).

Table 4. Comparison of success rates on D8.

\begin{tabular}{ccccc}
\hline & Treatment A & Treatment B & Difference (IC95\%) & $p$ Sup A vs. B \\
\hline ITT, worst-case for A & $22 / 22(100 \%)$ & $9 / 23(39.1 \%)$ & $60.9(35.8 ; 80.9)$ & $<0.0001$ \\
PP & $22 / 22(100 \%)$ & $7 / 21(33.3 \%)$ & $66.7(38.5 ; 85.4)$ & $<0.0001$ \\
\hline
\end{tabular}


3.1.3. Results for the Criteria "Absence of Live Lice and Live Immature on D2" and "Absence of Live Lice and Immature Lice on D1"

Since we are at D2 and at D1, the notion of exogenous re-infestation is not to be considered. The results show 21/22 (95.5\%) cured for treatment A, 12/23 (52.2\%) and 11/22 (50/0\%) for treatment B at Day 2 and Day 1, respectively (Table 5). The results are the same for both strategies.

Table 5. Comparison of success rates at D2 and at D1.

\begin{tabular}{ccccc}
\hline At Day 2 & Treatment A & Treatment B & Difference (IC95\%) & $p$ Sup A vs. B \\
\hline $\begin{array}{c}\text { ITT, worst-case for A } \\
\text { PP }\end{array}$ & $21 / 22(95.5 \%)$ & $12 / 23(52.2 \%)$ & $43.3(16.0 ; 67.3)$ & 0.0005 \\
21/22 (95.5\%) & $11 / 22(50 / 0 \%)$ & $45.5(14.4 ; 70.1)$ & 0.0004 \\
\hline $\begin{array}{c}\text { At Day 1 } \\
\begin{array}{c}\text { TTT, worst-case for A } \\
\text { / PP }\end{array}\end{array}$ & 21/22 (95.5\%) & $12 / 23(52.2 \%)$ & $43.3(16.0 ; 67.3)$ & 0.0005 \\
\hline
\end{tabular}

3.1.4. Criterion "Absence of Live Lice on D1 and D2 and Absence of Live Immatures on D8"

In ITT, regarding the "worst case" and under the efficacy criterion "no living lice at D1 and D2 and no living immature at D8", data show 95.5\% success for the new pediculicide and $39.1 \%$ for the $1 \%$ Permethrin, with a difference of 56.3\% (30.7; 77.6), $p$ sup A vs. B < 0.0001 (Table 6).

Table 6. Cure rate of the two treatments: intent-to-treat (ITT) and per protocol (PP).

\begin{tabular}{ccccc}
\hline & Treatment A & Treatment B & Difference (IC95\%) & $p$ Sup A. vs. B \\
\hline ITT, worst-case for A & $21 / 22(95.5 \%)$ & $9 / 23(39.1 \%)$ & $56.3(30.7 ; 77.6)$ & $<0.0001$ \\
PP & $21 / 22(95.5 \%)$ & $7 / 21(33.3 \%)$ & $62.1(33.1 ; 82.0)$ & $<0.0001$ \\
\hline
\end{tabular}

Table 7 summarizes the results for each criterion, for the primary endpoint and secondary endpoints in vivo, intent-to-treat, and per-protocol analyses.

Table 7. Success rate per treatment, following the different criteria for the cure of infestation.

\begin{tabular}{|c|c|c|c|c|}
\hline & Treatment A & Treatment B & Difference (IC95\%) & $P$-Value \\
\hline \multicolumn{5}{|l|}{ Intent-to-treat * } \\
\hline Treatment success at D8 ${ }^{\dagger}$ & $21 / 22(95.5 \%)$ & $9 / 23(39.1 \%)$ & $56.3(30.7 ; 77.6)$ & $<0.0001$ \\
\hline No alive lice at D8 $\ddagger$ & $21 / 22(95.5 \%)$ & $12 / 23(52.2 \%)$ & $43.3(16.0 ; 67.3)$ & 0.0005 \\
\hline No alive nymphs at D8 & $22 / 22(100 \%)$ & $9 / 23(39.1 \%)$ & $60.9(35.8 ; 80.9)$ & $<0.0001$ \\
\hline $\begin{array}{c}\text { No alive lice and no alive } \\
\text { nymph at D1 }\end{array}$ & $21 / 22(95.5 \%)$ & $12 / 23(52.2 \%)$ & $43.3(16.0 ; 67.3)$ & 0.0005 \\
\hline $\begin{array}{c}\text { No alive lice and no alive } \\
\text { nymph at D2 }\end{array}$ & $21 / 22(95.5 \%)$ & $12 / 23(52.2 \%)$ & $43.3(16.0 ; 67.3)$ & 0.0005 \\
\hline \multicolumn{5}{|l|}{ Per protocol } \\
\hline Treatment success at D8 ${ }^{\dagger}$ & $21 / 22(95.5 \%)$ & $7 / 21(33.3 \%)$ & $62.1(33.1 ; 82.0)$ & $<0.0001$ \\
\hline No alive lice at $\mathrm{D} 8 \ddagger$ & $21 / 22(95.5 \%)$ & $10 / 21(47.6 \%)$ & $47.8(17.6 ; 70.4)$ & 0.0003 \\
\hline No alive nymphs at D8 & $22 / 22(100 \%)$ & $7 / 21(33.3 \%)$ & $66.7(38.5 ; 85.4)$ & $<0.0001$ \\
\hline $\begin{array}{c}\text { No alive lice and no alive } \\
\text { nymph at D1 }\end{array}$ & $21 / 22(95.5 \%)$ & $12 / 23(52.2 \%)$ & $43.3(16.0 ; 67.3)$ & 0.0005 \\
\hline $\begin{array}{c}\text { No alive lice and no alive } \\
\text { nymph at D2 }\end{array}$ & $21 / 22(95.5 \%)$ & $11 / 22(50.0 \%)$ & $45.5(14.4 ; 70.1)$ & 0.0004 \\
\hline
\end{tabular}

${ }^{*}$ Worst-case analysis for A. ${ }^{\dagger}$ No live lice at D1 and D2 and no live nymphs at D8. ${ }^{\ddagger}$ Including the children with exogenous reinfection and considering them as a success. II Signification degree (unilateral) of the superiority test $\mathrm{A}$ vs. B.

\subsubsection{Additional Analyses}

We noticed that the early results were already very satisfactory for treatment A. We crossed the results "absence of live lice and live immature D1" with "absence of live lice on D1 and D2 and absence of live immatures on D8". The results were as follows (Tables 8 and 9): 
Table 8. Results for treatment A.

\begin{tabular}{lccc}
\hline & & \multicolumn{2}{c}{$\begin{array}{c}\text { Absence of Alive Lice on D1 and D2 and } \\
\text { Absence of Living Immatures on D8 }\end{array}$} \\
\hline & & No & Yes \\
Absence of alive lice and & No & 1 & 0 \\
living immatures on D1 & Yes & 0 & 21 \\
\hline
\end{tabular}

Table 9. Results for treatment B.

\begin{tabular}{lccc}
\hline & & $\begin{array}{c}\text { Absence of Alive Lice on D1 and D2 and } \\
\text { Absence of Living Immatures on D8 }\end{array}$ \\
\hline & & No & Yes \\
Absence of alive lice and & No & 11 & 0 \\
living immatures on D1 & Yes & 3 & 9 \\
\hline
\end{tabular}

Thus, of the 21 children having neither immature living nor louse living on D1, 21 (therefore, 100\%) were considered as cured on D8 (absence of live lice on D1 and D2 and absence of living immature on D8).

Among the 12 children with neither immature living nor louse living on D1, 9 (or 75\%) were considered to be cured on D8 (absence of live lice on D1 and D2 and absence of living immatures on D8). We can conclude that the rate of children cured on D8 differs depending on the treatment ( $p=$ 0.04). The results were exactly the same with D2.

\subsection{Ovicidal Efficacy of the Two Treatments, in Vitro Part of the Study}

The outcome was the frequency of ovicidal failure, measured by the percentage of hatched eggs in the incubator and measured by the imago viability at three hours after hatching.

\subsubsection{Comparison of Cumulative Hatching Rates on D10}

If we look at D10 and compare the rates (total number of outbreaks/total number removed) of children with treatment (A vs. B), we obtain the following results: cumulative hatching rate at D10 is 1.8 (6.6) for the new pediculicide and 53.7 (26.5) for the $1 \%$ Permethrin. Rate of viable nymphs is 0.5 (2.1) for the new pediculicide and 40.8 (20.4) for the $1 \%$ Permethrin. Thus, on D10, the risk of hatching with treatment $A$ is multiplied by 0.017 (divided by 60). In the same way, the risk of viable hatching with treatment $\mathrm{A}$ is multiplied by 0.007 (divided by 140) (Table 10).

Table 10. Hatching rate of eggs for the two treatments.

\begin{tabular}{|c|c|c|c|c|c|}
\hline & Treatment A & Treatment B & Odds-Ratio & IC95\% & $p$ \\
\hline Hatching rate $(\%)$ & $1.8(6.6)$ & $53.7(26.5)$ & 0.017 & $(0.006 ; 0.049)$ & $<0.0001$ \\
\hline Hatching rate of viable nymphs (\%) & $0.5(2.1)$ & $40.8(20.4)$ & 0.007 & $\begin{array}{c}(<0.001 ; \\
0.055)\end{array}$ & $<0.0001$ \\
\hline
\end{tabular}

\subsubsection{Comparison of Cumulative Hatching Rates from D2 to D10}

Including in the analysis, the observations of children with treatments from D2 to D10, we highlight a treatment effect and a time effect (Table 11; Figure 3; Figure 4), but we cannot include an interaction between the two factors, because the model does not converge. The risk of hatching with treatment $\mathrm{A}$ is divided by $1 / 0.023$ (a little more than 40 ), whatever the time considered. The risk of viable hatching with treatment $\mathrm{A}$ is divided by 1/0.010 (100), whatever the time considered. 
Table 11. Hatching rate of eggs for the two treatments.

\begin{tabular}{cccc}
\hline & Odds-Ratio A vs. B & IC95\% & $p$ \\
\hline Hatching rate (\%) & 0.023 & $(0.007 ; 0.074)$ & $<0.0001$ \\
Hatching rate of viable nymphs (\%) & 0.010 & $(0.002 ; 0.050)$ & $<0.0001$ \\
\hline
\end{tabular}

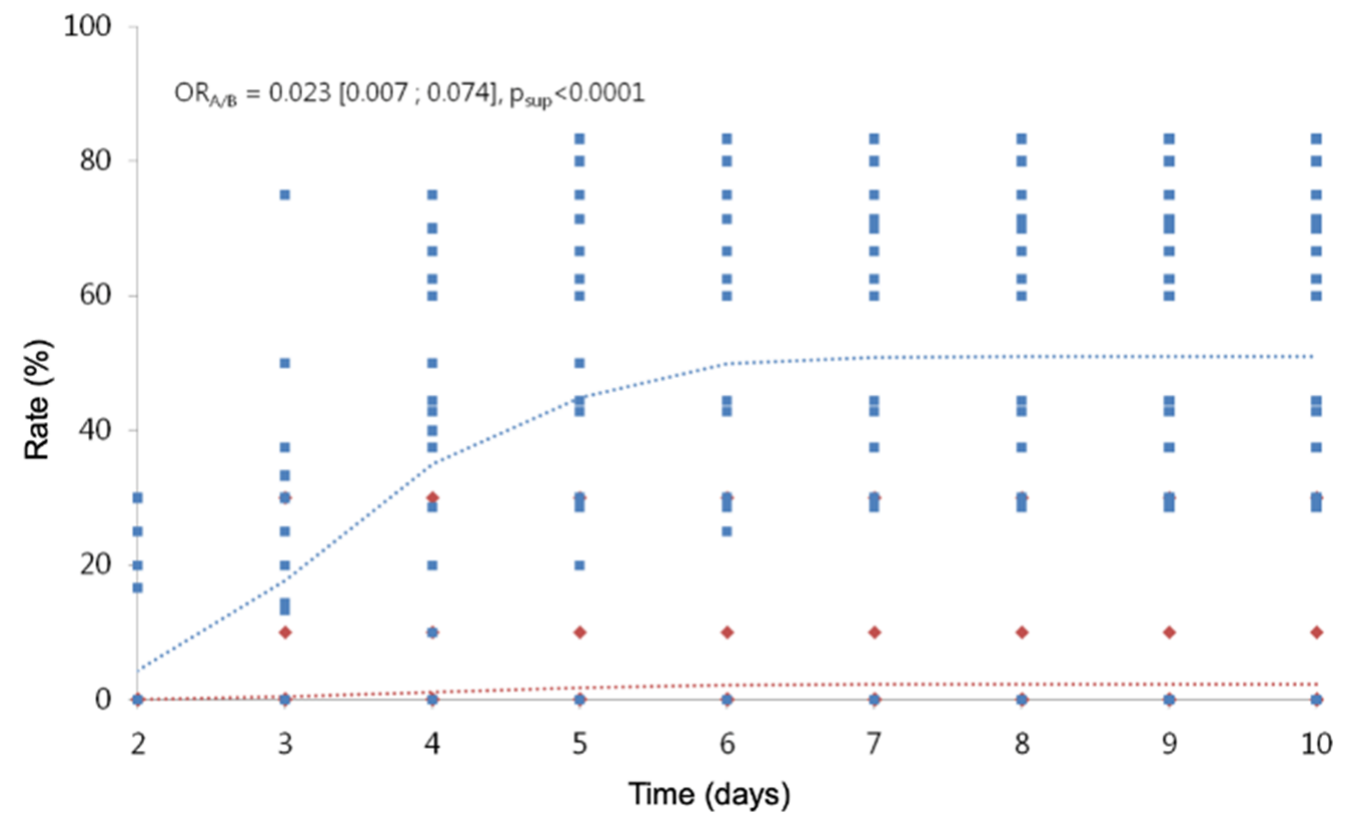

Figure 3. Cumulative hatching rate over time. In red, the observed (diamond symbols) and predicted (dotted line) values for treatment A. In blue, the observed (square symbols) and predicted (dotted line) values for treatment $B$.

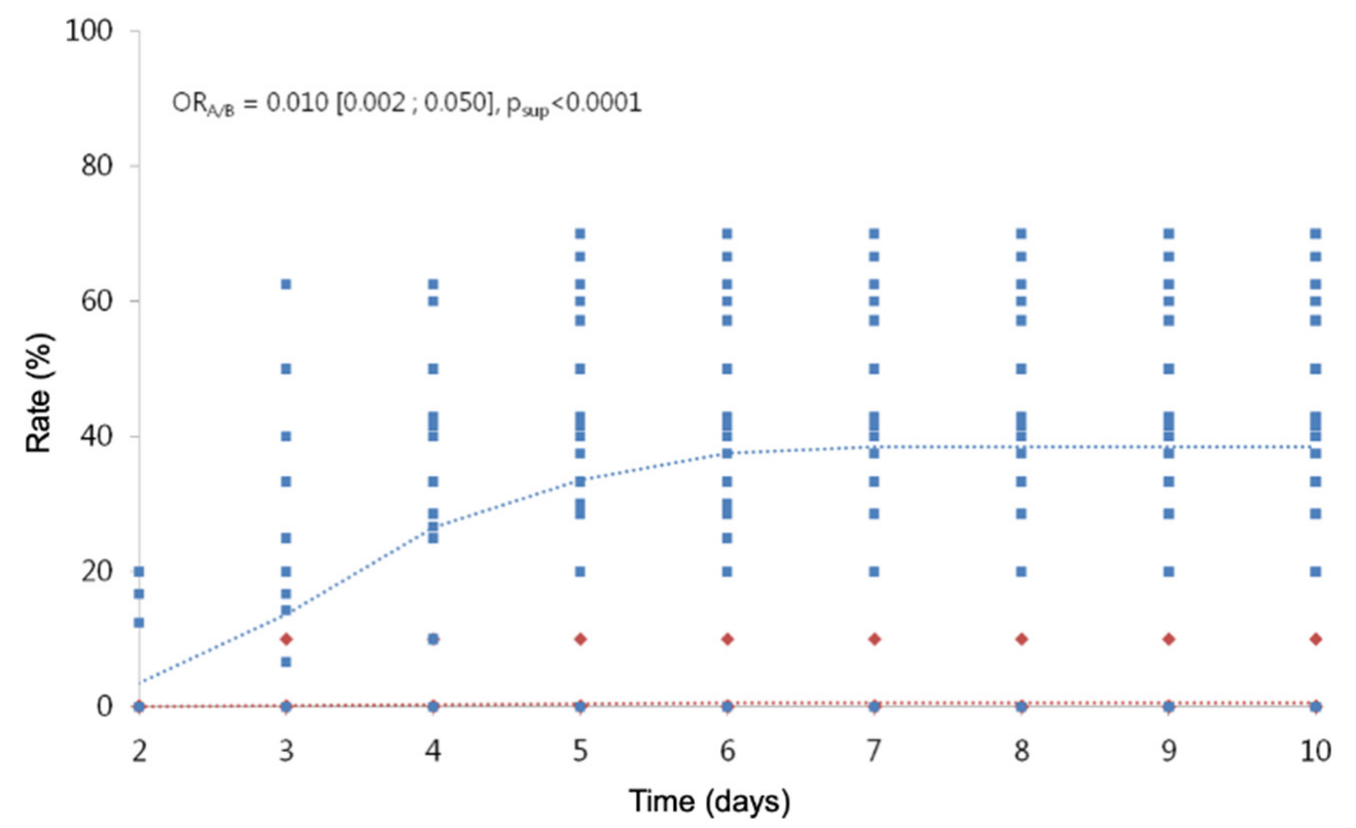

Figure 4. Cumulative hatching rates of viable nymphs over time. In red, the observed (diamond symbols) and predicted (dotted line) values for treatment A. In blue, the observed (square symbols) and predicted (dotted line) values for treatment $B$. 


\section{Discussion}

This study has shown that a single application of the new lotion made by semi-crystalline polymers and plant extracts is effective to eliminate in $15 \mathrm{~min}$ head louse infestation and to inhibit eggs hatching. However, as with all treatments, it is possible to miss some louse eggs during treatment, requiring post-treatment vigilance for emerging nymphs more than seven days after treatment. In this study, four infestations in the ITT group without nymphs (one in group B and three in group A) were attributable to reinfestation from contacts either within the family or the local community.

As the participants went back home each night, a high risk of reinfestation after a cure was expected. Knowledge of family circumstances (siblings) helped us to identify some reinfestation risks, but for statistical purposes, we specified criteria for exogenous reinfestation: no live lice found after the treatments at days 1 and day 2 and, on day 8, no more than four adult lice and no nymphs found during combing. We acknowledge these criteria could give false outcomes either way, but we believe they addressed the issue of reinfestation without presenting an unreasonably optimistic view of the product efficacy. The presence of small lice (nymphs) was evidence that not all the eggs were killed by the treatment.

Furthermore, in vitro analysis of the hatching rate of lice eggs helped us determine whether the presence of any louse was due to surviving phenomenon or due to the survival of any egg, from which nymph was able to emerge. In vitro experiment was useful to determine the specific efficacy of each treatment on the hatching rate of eggs in order to maximize the power of the study. This in vitro study had a strong interest in order to discriminate between a treatment failure and a recontamination by the environment and to ensure that the protocol was not broken by families at home. An occasional adult louse found after the initial infestation was clearly the indicator of an exogenous reinfestation. Criteria for a cure of infestation was defined with the most demanding criteria, as no evidence of living head lice after treatment at day 1 and no evidence of living head lice at day 2 and no evidence of living immature head lice at day 8 . Any participant not fitting the cure criteria or exogenous reinfestation criteria after the cure was categorized as a treatment failure.

Regarding the study protocol of intervention, we chose to harmonize the application for the two products tested, in order to optimize the comparison conditions and to permit a double-blind trial. We have taken as standard the recommendations for use of the manufacturer of the new treatment, because the permethrin is not known for basing its mode of action and, therefore, its efficacy on the mechanical manipulations linked to the product application, contrary to the technology and the mechanical mode of action claimed for the new lotion (DeparazßParaPioß). Contrary to the manufacturer's recommendations for the Permethrin 1\% (Pediletan $囚)$, no rigorous combing was performed before treatment removal. Furthermore, for the two treatments, no rigorous combing was made immediately after treatment removal, because this modality would lead to a serious bias regarding the efficacy measure of each lotion themselves.

The efficiency of this new lotion seems to consist in the plant's resin Protium heptaphyllum mechanical action, easily distributed along the hair and on the parasites thanks to Eur-Amid N2@, by decreasing the surface tension. Citrus aurantium dulcis peel wax consists of a complex mixture of special esters (ca. 50\%-65\%, C44-C58), free fatty acids (6\%-15\%,C14-C22), hydrocarbons (8\%-15\%, C21-C33), free phytosterols (ca. 4\%-8\%), and free alcohols. It is used to stabilize the mixture. Eur-Amid N2@and phytosterols help to dissolve the epicuticular waxes that cover the shells of the parasites. As a result, the chitin becomes accessible to the resin. We observed that the Protium heptaphyllum resin, usually used as a film-forming agent in cosmetics, seems to have some specific affinities for the chitin (polysaccharides) of the parasites. There is a phenomenon of coating of the shell of lice and their nits.

The liquefied resin has the property to stiffen under contact with aqueous polar environment. That is the reason why the mixture has to be put in contact with water after the exposure time. In contact with water, the resin hardens and shrinks by a few microns. This phenomenon seems to cause cracking of the rigid shell of the parasites. This mechanism leads to a breakdown of external defenses and normal biological functions of lice and nits. It seems to happen as a perforation and dislocation of 
the rigid shell and the paws of lice (Figures 5 and 6), and the operculum of the nits is covered with resin, which seems to destroy its opening-closing mechanism (Figures 7-9). Under these conditions, lice are paralyzed, unable to move, feed, and reproduce. So, parasites are easily eliminated by the shampoo, because they cannot hang on to the hair anymore, and nits still hanging in the hair are no longer viable because the exchanges between them and their environment were disrupted by the destruction of the protective articulated operculum.

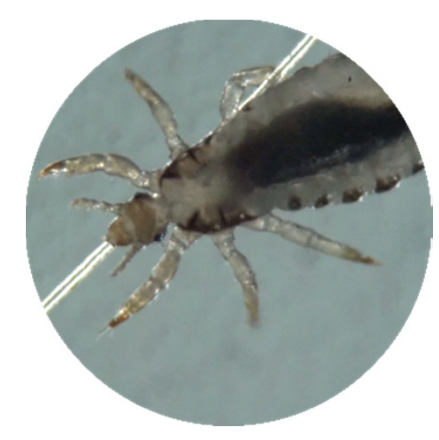

Figure 5. Louse before treatment. Binocular magnifier, Leica M50.

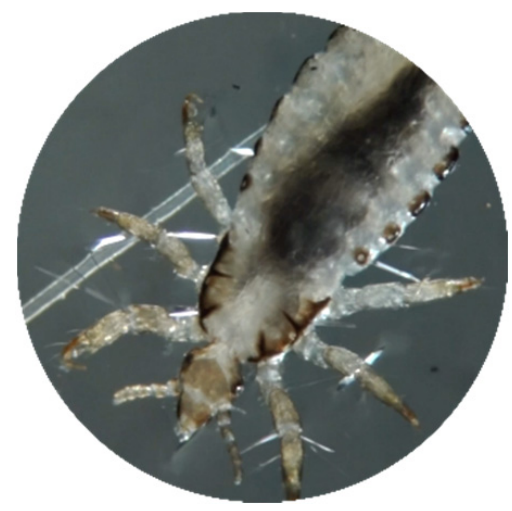

Figure 6. Louse after treatment. External solidification of the resin on the chitin (polysaccharides). Binocular magnifier, Leica M50.

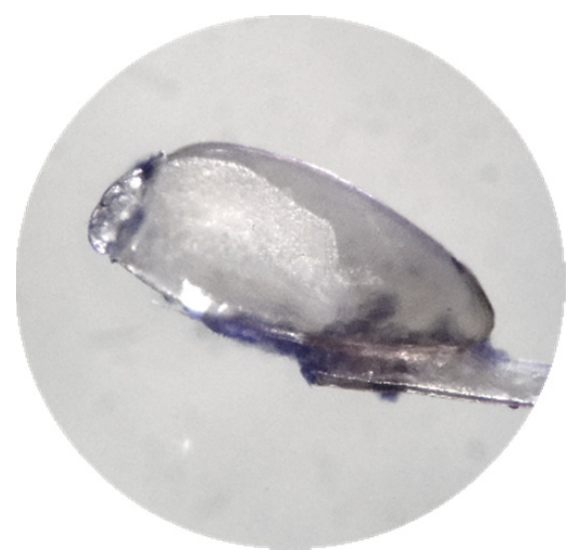

Figure 7. Nit before treatment. Binocular magnifier, Leica M50. 


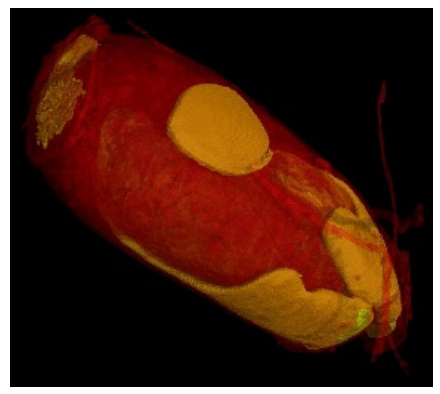

Figure 8. PET Scan 3D of a nit. Affinity of the resin for the nit (orange areas). Ultra-high resolution scanner photo $(0.9 \mu \mathrm{m})$. 3D impressions and the exported slices in the right and top direction $(1.15 \mu \mathrm{m})$. Reconstruction of the zoom scan $(0.9 \mu \mathrm{m})$ (Tescan Technology).

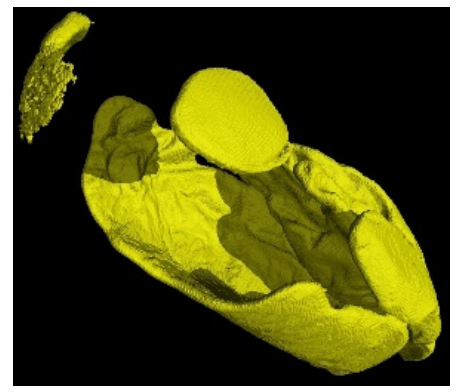

Figure 9. 3D reconstruction of the fixation of P. Heptaphyllum resin on a nit.

This product does not damage the hair and the scalp. After shampoo, the hair benefits from the resin residue, playing the role of conditioner. Furthermore, grapeseed oil nourishes the hair thanks to the presence of fatty acids such as Omega-6; orange peel wax is often used as hair care in cosmetics, and Eur-Amid N2@is a mild nonionic surfactant used for its good foaming and viscosity-building properties, usually employed in shampoos. These surfactants are designed for imparting smoothness to skin and appreciated for children who present itching scalps due to repeated lice bites. Other benefits are the potential reduction of the irritation of anionic surfactants to skin and eyes, being a safer liquid alternative to cocamide DEA and having a vegetable origin. Finally, the anti-inflammatory properties of amyrin can also soothe itchy, irritated scalps in children.

\section{Conclusions}

Considering the results provided by this study for the killing of lice and eggs rates and regarding its directions for use (no necessary combing), the new lotion could be an interesting way to eradicate lice from the communities. It is possible that this treatment can be used frequently, because the parasites are killed mechanically and not by some neurotoxic agents. Lice may not be able to develop genetic resistance to this type of mechanical action treatment. This approach seems to be a promising alternative also considering its natural composition and the anti-inflammatory properties of some of its components.

Author Contributions: Conceptualization: J.H.L.C., F.M.d.S. and C.P.; methodology, J.H.L.C. and C.P.; software, C.P.; validation, J.H.L.C. and C.P.; formal analysis, C.P.; investigation, F.M.d.S. and S.S.P.; data curation, A.N.C.d.S.; writing-original draft preparation, A.N.C.d.S., F.M.d.S., S.S.P.; writing-review and editing, J.H.L.C., C.P.; supervision, J.H.L.C.; project administration, A.N.C.d.S. All authors have read and agreed to the published version of the manuscript.

Funding: This research received no external funding.

Acknowledgments: We thank Laboratoire DUHOT sprl, Belgium for providing the sufficient bottles of the lotion Deparaz/ParaPio@to carry out the tests, for allowing the purchase of the treatment we chose as a positive control

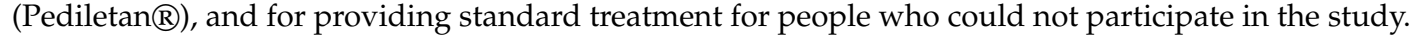


Conflicts of Interest: The authors have declared that they have no conflicts of interest regarding the contents of this article. They do not receive financial compensation for their work. School staff and participants do not receive financial compensation.

\section{References}

1. Chosidow, O. Scabies and pediculosis. Lancet 2000, 355, 819-826. [CrossRef]

2. Frankowski, B.L.; Bocchini, J.A. Head lice. Pediatrics 2010, 126, 392-403. [CrossRef] [PubMed]

3. Durand, R.; Bouvresse, S.; Berdjane, Z.; Izri, A.; Chosidow, O.; Clark, J.M. Insecticide resistance in head lice: Clinical, parasitological and genetic aspects. Clin. Microbiol. Infect. 2012, 18, 338-344. [CrossRef] [PubMed]

4. Pearlman, D.L. A simple treatment for head lice: Dry-on, suffocation-based pediculicide. Pediatrics 2004, 114, 275-279. [CrossRef]

5. Richling, I.; Böckeler, W. Lethal Effects of Treatment with a Special Dimeticone Formula on Head Lice and House Crickets (Orthoptera, Ensifera: Acheta domestica and Anoplura, Phthiraptera: Pediculus humanus). Arzneimittelforschung 2008, 58, 248-254. [CrossRef]

6. Burgess, I.F.; Brown, C.M.; Lee, P.N. Treatment of head louse infestation with $4 \%$ dimeticone lotion: Randomised controlled equivalence trial. BMJ 2005, 330, 1423. [CrossRef]

7. Lebwohl, M.; Clark, L.; Levitt, J. Therapy for head lice based on life cycle, resistance, and safety considerations. Pediatrics 2007, 119, 965-974. [CrossRef]

8. Chosidow, O.; Giraudeau, B.; Cottrell, J.; Izri, A.; Hofmann, R.; Mann, S.G.; Burgess, I. Oral ivermectin versus malathion lotion for difficult-to-treat head lice. N. Engl. J. Med. 2010, 362, 896-905. [CrossRef]

9. Heukelbach, J.; Oliveira, F.A.; Richter, J.; Häussinger, D. Dimeticone-based pediculicides: A physical approach to eradicate head lice. Open Dermatol. J. 2010, 4, 77-81. [CrossRef]

10. Mehlhorn, H.; Abdel-Ghaffar, F.; Al-Rasheid, K.A.; Schmidt, J.; Semmler, M. Ovicidal effects of a neem seed extract preparation on eggs of body and head lice. Parasitol. Res. 2011, 109, 1299-1302. [CrossRef]

11. Combescot-Lang, C.; Vander Stichele, R.H.; Toubate, B.; Veirron, E.; Mumcuoglu, K.Y. Ex vivo effectiveness of French over-the-counter products against head lice (Pediculus humanus capitis De Geer, 1778). Parasitol. Res. 2015, 114, 1779-1792. [CrossRef]

12. Mumcuoglu, K.Y.; Miller, J.; Zamir, C.; Zentner, G.; Helbin, V.; Ingber, A. The in vivo pediculicidal efficacy of a natural remedy. Isr. Med. Assoc. J. IMAJ 2002, 4, 790-793. [PubMed]

13. Kurt, O.; Balcioglu, I.C.; Burgess, I.F.; Limoncu, M.E.; Girginkardeşler, N.; Tabak, T.; Muslu, H.; Ermiş, O.; Sahin, M.T.; Bilac, C.; et al. Treatment of head lice with dimeticone $4 \%$ lotion: Comparison of two formulations in a randomised controlled trial in rural Turkey. BMC Public Health 2009, 9, 441. [CrossRef] [PubMed]

14. Burgess, I.F.; Burgess, N.A. Dimeticone $4 \%$ liquid gel found to kill all lice and eggs with a single 15 minute application. BMC Res. Notes 2011, 4, 15. [CrossRef] [PubMed]

15. Heukelbach, J.; Pilger, D.; Oliveira, F.A.; Khakban, A.; Ariza, L.; Feldmeier, H. A highly efficacious pediculicide based on dimeticone: Randomized observer blinded comparative trial. BMC Infect. Dis. 2008, 8, 115. [CrossRef] [PubMed]

16. Weeks, A.; Daly, D.C.; Simpson, B.B. The phylogenetic history and historical biogeography of the frankincense and myrrh family (Burseraceae) based on nuclear and chloroplast sequence data. Mol. Phylogenet. Evol. 2005, 35, 85-101. [CrossRef]

17. Lima, E.M.; Nascimento, A.M.; Lenz, D.; Scherer, R.; Meyrelles, S.S.; Boëchat, G.A.P.; Andrade, T.U.; Endringer, D.C. Triterpenes from the Protium heptaphyllum resin-chemical composition and cytotoxicity. Rev. Bras. Farmacogn. 2014, 24, 399-407. [CrossRef]

18. Lorenzi, H. Árvores Brasileiras: Manual de Identificação e Cultivo de Plantas Arbóreas Nativas do Brasil, 3rd ed.; Instituto Plantarum: Nova Odessa, Brazil, 2008.

19. Lorenzi, H.; Matos, F.J.A. Medicinal Plants in Brazil: Native and Exotic; Instituto Plantarum: Nova Odessa, Brazil, 2008.

20. Corrêia, M. Dictionary of Useful Plants of Brazil; National Press: Rio de Janeiro, Brazil, 1926; Volume 1.

21. Ndinga, A.M.E. Inventaire et Analyse Chimique des Exsudats des Plantes d'Utilisation Courante au Congo-Brazzaville. Ph.D. Thesis, Chimie analytique. Université Paris Sud - Paris XI. Université MarienNgouabi, Brazzaville, Congo, 2015. 
22. Langenheim, J.H. Plant Resins: Chemistry, Evolution, Ecology and Ethnobotany; Timber Press: Portland, OR, USA, 2003.

23. Oliveira, F.A.; Vieira-Júnior, G.M.; Chaves, M.H.; Almeida, F.R.; Florêncio, M.G.; Lima, R.C., Jr.; Rao, V.S. Gastroprotective and anti-inflammatory effects of resin from Protium heptaphyllum in mice and rats. Pharmacol. Res. 2004, 49, 105-111. [CrossRef]

24. Susunaga, G.S. Estudo Químico e Biológico da Resina Produzida pela Espécie Protium heptaphyllum March. (Burseraceae). Master's Thesis, Universidade Federal do Amazonas, Manaus, Brazil, 1996; pp. 1-163.

25. Siani, A.C.; Ramos, M.F.S.; Menezes, O.; Ribeiro, R.; Fernandez, E.; Soares, R.O.; Rosas, E.C.; Susunaga, G.S.; Guimarães, A.C.; Zoghbi, M.G.; et al. Evaluation of antiinflamatory-related activity of essential oils from the leaves and resin of species of Protium. J. Ethnopharmacol. 1999, 66, 57-69. [CrossRef]

26. Bandeira, N.; Fonseca, A.M.; Costa, S.M.O.; Lins, M.U.D.S.; Pessoa, O.D.L.; Monte, F.J.Q.; Lemos, T.L.G. Antimicrobial and antioxidant activities of the essential oil of resin of Protium heptaphyllum. Nat. Prod. Commun. 2006, 1, 1934578X0600100207. [CrossRef]

27. Oliveira, F.A. Estudo das Atividades Farmacológicas da Resina de Protium hetaphyllum (Aubl.) March. e de seus Principais Constituintes, Mistura de $\alpha$ e $\beta$ Amirina. Ph.D. Thesis, Universidade Federal do Ceará, Fortaleza, Brazil, 2005; pp. 1-242.

28. Maia, R.M.; Barbosa, P.R.; Cruz, F.G.; Roque, N.F.; Fascio, M. Triterpenos da resina de Protium heptaphyllum March (Bourseraceae): Caracterização em misturas binárias. Quim. Nova 2000, 23, 623-626. [CrossRef]

29. Rüdiger, A.L.; Siani, A.C.; Junior, V.V. The chemistry and pharmacology of the South America genus Protium Burm. f.(Burseraceae). Pharmacogn. Rev. 2007, 1, 93-104.

30. Feldmeier, H. Pediculosis capitis: New insights into epidemiology, diagnosis and treatment. Eur. J. Clin. Microbiol. Infect. Dis. 2012, 31, 2105-2110. [CrossRef] [PubMed]

31. Balcioglu, C.; Burgess, I.F.; Limoncu, M.E.; Şahin, M.T.; Ozbel, Y.; Bilac, C.; Larsen, K.S. Plastic detection comb better than visual screening for diagnosis of head louse infestation. Epidemiol. Infest. 2008, 136, 1425-1431. [CrossRef]

32. Ash, M. Handbook of Preservatives; Synapse Info Resources: Endicott, NY, USA, 2004; p. 474.

33. Meinking, T.L.; Clineschmidt, C.M.; Chen, C.; Kolber, M.A.; Tipping, R.W.; Furtek, C.I.; Guzzo, C.A. An observer-blinded study of $1 \%$ permethrin creme rinse with and without adjunctive combing in patients with head lice. J. Pediatrics 2002, 141, 665-670. [CrossRef]

34. Meinking, T.L.; Vicaria, M.; Eyerdam, D.H.; Villar, M.E.; Reyna, S.; Suarez, G. Efficacy of a reduced application time of Ovide lotion ( $0.5 \%$ malathion) compared to Nix creme rinse ( $1 \%$ permethrin) for the treatment of head lice. Pediatric Dermatol. 2004, 21, 670-674. [CrossRef]

35. Hipolito, R.B.; Mallorca, F.G.; Zuniga-Macaraig, Z.O.; Apolinario, C.; Wheeler-Sherman, J. Head louse infestation: Single drug versus combination therapy with one percent permethrin and trimethoprim/sulfamethoxazole. Pediatrics 2001, 107, 30. [CrossRef]

36. Carson, D.S.; Tribble, W.; Weart, C.W. Pyrethrins combined with piperonyl butoxide (RID) vs $1 \%$ permethrin (NIX) in the treatment of head lice. Am. J. Dis. Child. 1988, 142, 768-769. [CrossRef]

37. Serrano, L.; Decesar, L.S.; Pham, L. Evaluation of the efficacy and safety of $1 \%$ sodium chloride (LiceFreee Spray) against $1 \%$ permethrin crème rinse on head lice infested individuals. Pharmacol. Pharm. 2013, 4, 266-273. [CrossRef]

38. Downs, A.M.R.; Stafford, K.A.; Harvey, I.; Coles, G.C. Evidence for double resistance to permethrin and malathion in head lice. Br. J. Dermatol. 1999, 141, 508-511. [CrossRef]

39. Meinking, T.L.; Vicaria, M.; Eyerdam, D.H.; Villar, M.E.; Reyna, S.; Suarez, G. A Randomized, Investigator-Blinded, Time-Ranging Study of the Comparative Efficacy of $0.5 \%$ Malathion Gel Versus Ovide ${ }^{\circledR}$ Lotion ( $0.5 \%$ Malathion) or Nix ${ }^{\circledR}$ Crème Rinse (1\% Permethrin) Used as Labeled, for the Treatment of Head Lice. Pediatric Dermatol. 2007, 24, 405-411. [CrossRef] [PubMed]

40. Burgess, I.F.; Brunton, E.R.; Burgess, N.A. Single application of $4 \%$ dimeticone liquid gel versus two applications of $1 \%$ permethrin creme rinse for treatment of head louse infestation: A randomised controlled trial. BMC Dermatol. 2013, 13, 5. [CrossRef] [PubMed]

41. Burgess, I.F.; Burgess, N.A.; Brunton, E.R. Tocopheryl acetate $20 \%$ spray for elimination of head louse infestation: A randomised controlled trial comparing with 1\% permethrin creme rinse. BMC Pharmacol. Toxicol. 2013, 14, 43. [CrossRef] [PubMed] 
42. Brandenburg, K.; Deinard, A.S.; DiNapoli, J.; Englender, S.J.; Orthoefer, J.; Wagner, D. 1\% permethrin cream rinse vs $1 \%$ lindane shampoo in treating pediculosis capitis. Am. J. Dis. Child. 1986, 140, 894-896. [CrossRef] [PubMed]

43. Taplin, D.; Meinking, T.L.; Castiliero, M.; Sanchez, R. Permethrin 1\% creme rinse for the treatment of Pediculus humanus var capitis infestation. Pediatric Dermatol. 1986, 3, 344-348. [CrossRef]

(C) 2020 by the authors. Licensee MDPI, Basel, Switzerland. This article is an open access article distributed under the terms and conditions of the Creative Commons Attribution (CC BY) license (http://creativecommons.org/licenses/by/4.0/). 